\title{
Correction to: Influence of foraminal enlargement on the healing of periapical lesions in rat molars
}

\author{
Paula Maciel Brandão ${ }^{1}$. José Antonio Poli de Figueiredo ${ }^{2} \cdot$ Renata Dornelles Morgental $^{3}$. \\ Roberta Kochenborger Scarparo ${ }^{4}$ Rafael Chies Hartmann ${ }^{2}$. Silvana Beltrami Gonçalves Waltrick ${ }^{2}$. \\ Ronaldo Araújo Souza ${ }^{1}$
}

Published online: 11 January 2019

(C) Springer-Verlag GmbH Germany, part of Springer Nature 2019

\section{Correction to: Clinical Oral Investigations \\ https://doi.org/10.1007/s00784-018-2628-2}

Figures 2 and 3 in the published version of this article contained a mistake. CCP and DCP should have been FEG and NFEG. Correct figures are presented here.

The original article has been corrected.

The online version of the original article can be found at https://doi.org/ $10.1007 / \mathrm{s} 00784-018-2628-2$

Renata Dornelles Morgental

remorgental@hotmail.com

1 Department of Endodontics, Bahia School of Medicine and Public Health, Avenida Dom João VI, 275, Salvador, BA 40290-000, Brazil

2 Clinical Department, School of Dentistry, Pontifical Catholic University of Rio Grande do Sul, Avenida Ipiranga, 6681, Porto Alegre, RS 90619-900, Brazil

3 Department of Stomatology, School of Dentistry, Federal University of Santa Maria, Rua Marechal Floriano Peixoto, 1184, Santa Maria, RS 97015-372, Brazil

4 Department of Conservative Dentistry, School of Dentistry, Federal University of Rio Grande do Sul, Rua Ramiro Barcelos, 2492, Porto Alegre, RS 90035-004, Brazil 


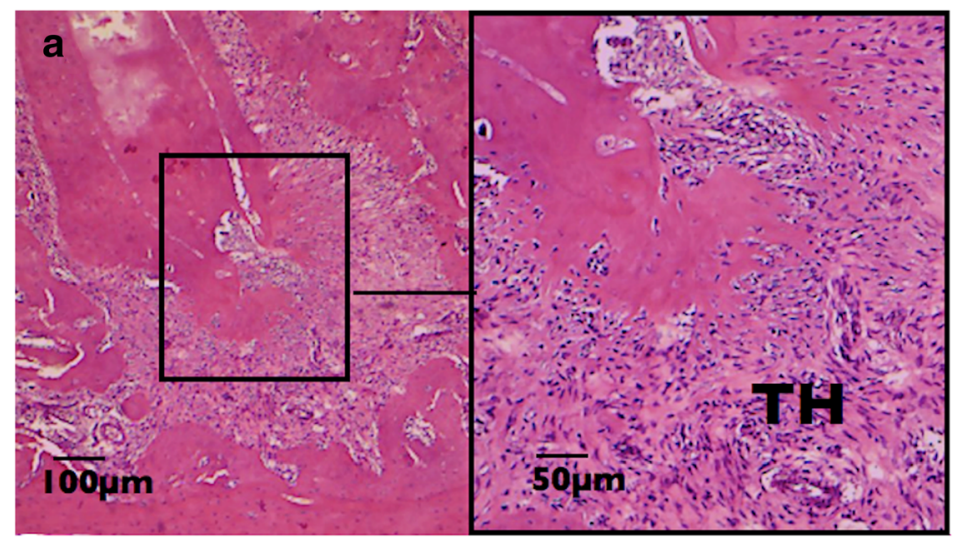

\section{C}
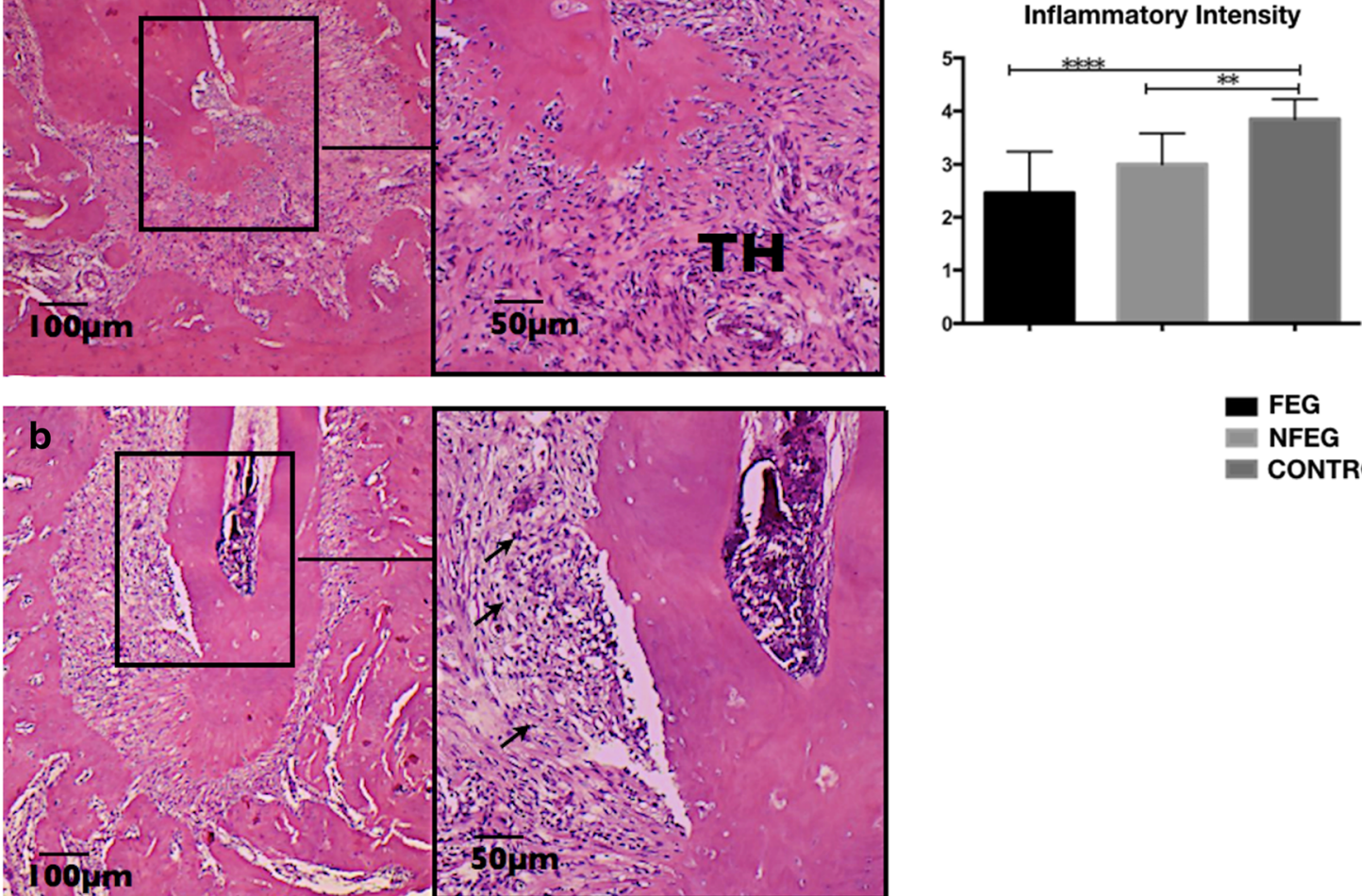

aEG

NFEG

CONTROL

Fig. 2 a Sample in which foraminal enlargement was preformed (FEG), showing periapical tissue healing $(\mathrm{TH})$ and absence of inflammatory infiltrate. b Periapical tissue reaction in a sample without foraminal enlargement (NFEG): moderate inflammatory infiltrate with sparse neutrophils restricted to the area close to the apical foramen (arrows). c
Both FEG and NFEG showed less intense inflammatory infiltrate compared to the control $(* * * * p<.0001$ and $* * p<.01)$. Significant differences of inflammation intensity were not detected between the experimental groups, although NFEG scored slightly higher 


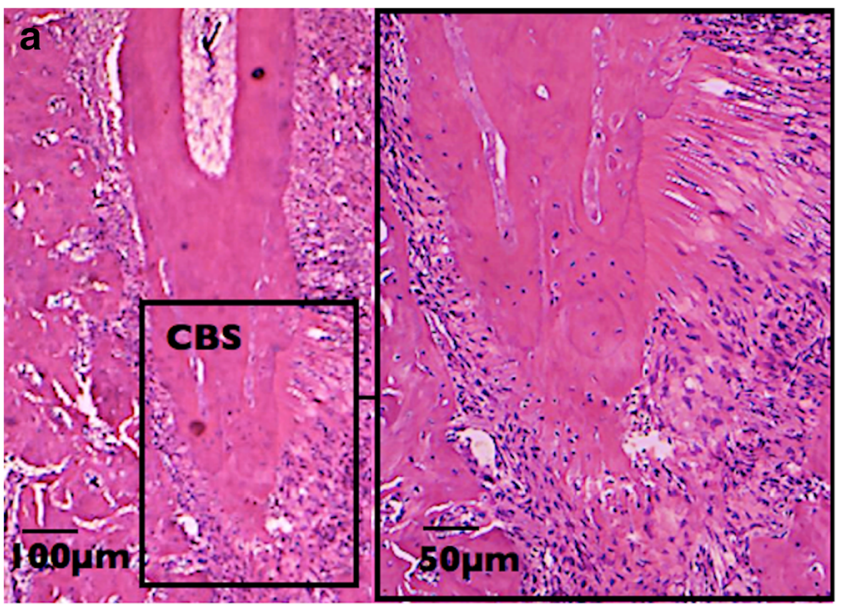

C

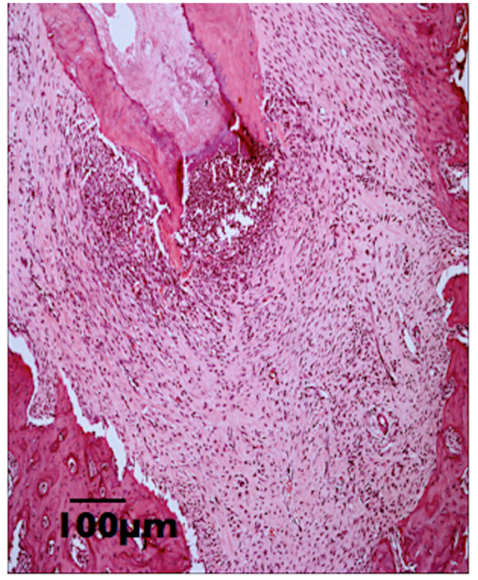

d
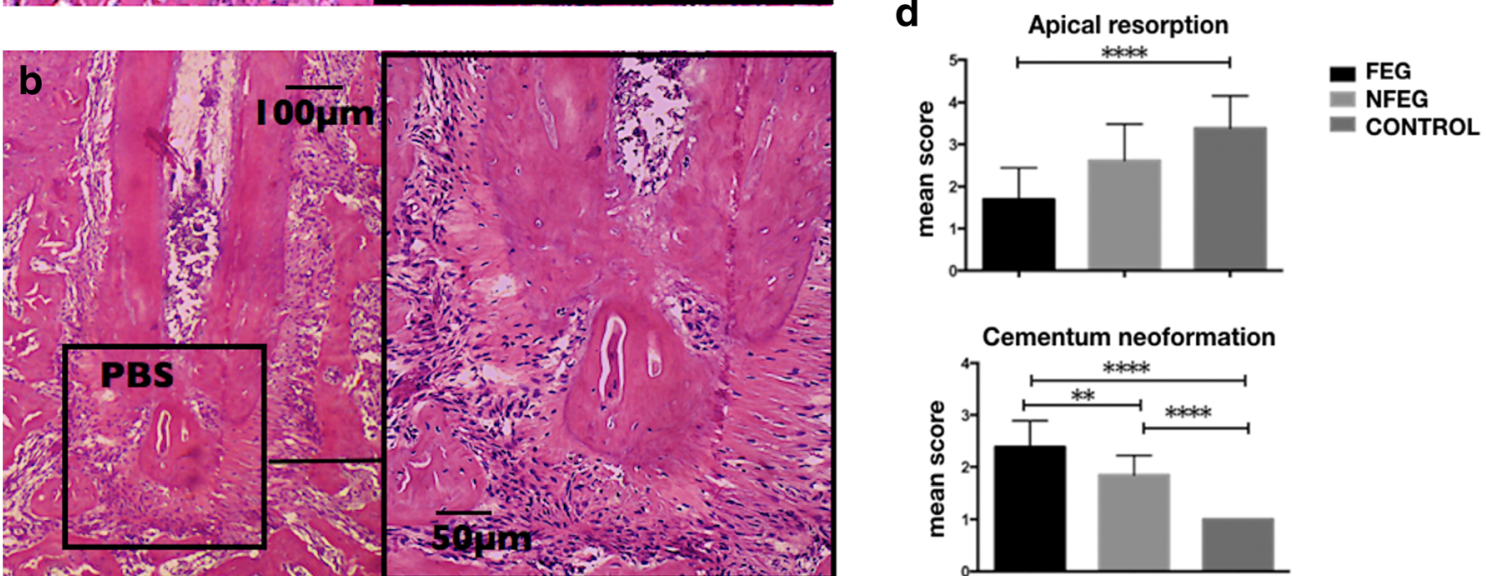

Fig. 3 a Absence of root resorption and complete biological seal (CBS) in a sample of foraminal enlargement group (FEG). b Absent dental resorption, cementum neoformation, and partial biological sealing (PBS) in a sample of non-foraminal enlargement group (NFEG). c Non-instrumented samples showed large areas of root resorption (arrows) and absence of neoformed cementum. $\mathbf{d}$ Both FEG and NFEG showed greater cementum neoformation compared to the control (****p $<$.0001). Significant differences were also observed comparing FEG and NFEG $(* * p<.01)$. Regarding root resorption, only samples instrumented in the entire root canal length (FEG) presented significantly decreased scores $(* * * p<.001)$ compared to the non-instrumented samples (control)

Publisher's Note Springer Nature remains neutral with regard to jurisdictional claims in published maps and institutional affiliations. 